\title{
ARTICLE
}

\section{Magnesium potassium phosphate matrix for immobilization of actinide-containing radioactive waste}

\author{
Sergey E. Vinokurov*, Svetlana A. Kulikova and Boris F. Myasoedov \\ Vernadsky Institute of Geochemistry and Analytical Chemistry of RAS, 19, Kosygin str., Moscow, 119991, Russian Federation
}

\begin{abstract}
Low-temperature mineral-like magnesium potassium phosphate matrix of various chemical compositions have been synthesized. Their phase composition, structure and distribution of radioactive waste components have been studied. The mechanical, thermal, radiation and hydrolytic stability of the synthesized materials have been investigated according to the valid regulatory requirements. It has been demonstrated that the magnesium potassium phosphate matrix is promising materials for industrial solidification of the liquid waste, including highly saline actinide-containing waste with complex chemical composition.
\end{abstract}

Keywords: magnesium potassium phosphate matrix; radioactive waste; ammonium; cesium; strontium; plutonium; europium; leaching rate; leaching mechanism

\section{Introduction}

Development prospects for the nuclear industry depend on the efficient solutions of the liquid radioactive waste (LRW) management. The waste should be transformed to a stable solidified form suitable for long-term controlled storage and/or disposal. Cement and glass are considered for the immobilization of actinide-containing radioactive waste (RW) of intermediate and high activity levels (ILW and HLW) [1]. Cementation is widely applied in the nuclear industry for the management of various kind of LRW. The main disadvantages of the method are relatively weak inclusion of LRW salts into cement, as well as low hydrolytic stability and frost resistance of cement containing waste salts. Vitrification is currently the only HLW management technology applied in industry. The main disadvantages of the method are low chemical and crystallization stability of glass at elevated temperatures, as well as short service life and high cost of melting equipment and gas cleaning systems. The search for a new matrix is of current interest due to the need in immobilization of new RW kinds with a complex chemical and radionuclide composition which contain highly toxic long-lived actinides and whose management with standard methods is not efficient.

The mineral-like materials are considered as an alternative to glass for the immobilization of RW containing long-lived radionuclides [2]. The magnesium potassium phosphate (MPP) matrix, $\mathrm{MgKPO}_{4} \cdot 6 \mathrm{H}_{2} \mathrm{O}$, is of particular interest $[3,4]$. It is a synthetic analogue of the natural mineral K-struvite [5] that can be synthesized at

*Corresponding author. Email: vinokurov.geokhi@gmail.com room temperature according to the reaction (1):

$$
\mathrm{MgO}+\mathrm{KH}_{2} \mathrm{PO}_{4}+5 \mathrm{H}_{2} \mathrm{O}=\mathrm{MgKPO}_{4} \cdot 6 \mathrm{H}_{2} \mathrm{O}
$$

In this work we present the results of the study of the phase composition and structure, mechanical strength, radiation, thermal and hydrolytic stability of the MPP matrix containing of RW components (hereinafter MPP compounds), including the MPP matrix obtained as a result of curing the highly saline solution simulating the industrial actinide-containing ILW.

\section{Experimental}

All experiments were performed in a glove box at ambient atmospheric conditions. The chemicals used in the experiments were of "chemical grade" purity or better. Samples of MPP compounds were synthesized according to the reaction (1). $\mathrm{MgO}$ has been precalcined at $1300^{\circ} \mathrm{C}$ for 3 hours; $\mathrm{KH}_{2} \mathrm{PO}_{4}$ with a particle size of 0.15-0.25 mm was used. Boric acid was added to the mixture to reduce the reaction (1) rate. The amount of boric acid was calculated for its content in the final compound to be $1.3 \pm 0.1 \%$ by weight.

The effect of the solution composition on the properties of the MPP compounds was determined during the immobilization of concentrated aqueous solutions of metal nitrates and ammonium nitrate simulating RW components, as well as the surrogate solution of actinide-containing LRW (mineralization $589 \mathrm{~g} / \mathrm{l}, \mathrm{pH}$ 5.6). The content of metals and ammonium in the synthesized MPP compounds, wt.\%: $\mathrm{Cs}-4.8$; $\mathrm{Sr}-6.7$; $\mathrm{NH}_{4}-3.4 ; \mathrm{Na}-3.5 ; \mathrm{La}-6.7 ; \mathrm{Fe}-1.4 ; \mathrm{Na}-3.3+\mathrm{NH}_{4}-$ 
$1.8+\mathrm{Eu}-0.2$. Specific activity of ${ }^{152} \mathrm{Eu}$ and ${ }^{239} \mathrm{Pu}$ in the synthesized samples was $4.0 \cdot 10^{3}$ and $1.6 \cdot 10^{5} \mathrm{~Bq} / \mathrm{g}$, respectively. The MPP compound samples with a mass of up to $50 \mathrm{~g}$ and a density of up to $2.0 \mathrm{~g} / \mathrm{cm}^{3}$ were obtained after gaining the strength in no less 15 days.

Phase composition of the synthesized samples was determined by X-ray diffraction (Ultima-IV, Rigaku). Surface morphology of the samples was studied by scanning electron microscopy (SEM) (LEOSupra $50 \mathrm{VP}$, Carl Zeiss) and X-ray microanalysis (X-Max 80, Oxford Inst.). Mechanical strength of the MPP compounds was determined on the Testing Sybertronic test machine, and the experiment on resistance to thermal cycles ( 30 cycles of freezing/thawing in the range from -40 to $+40^{\circ} \mathrm{C}$ ) was carried out in the MK-53 climate chamber. In studying the effect of mineral modifiers on the mechanical strength of MPP compounds, we used wollastonite (FW-200, Nordkalk), bentonite (10th Khutor deposit, Khakassia, Russia), and zeolite (Sokirnit, Transcarpathian deposit, clinoptilolite content 70\%). The modifiers were preliminarily ground and sieved, and the fraction with the $0.07-0.16 \mathrm{~mm}$ particle size was taken. Radiation stability was investigated by irradiation of the MPP compounds with a linear accelerator with a vertically scanning electron beam, the absorbed dose was no less than $1 \mathrm{MGy}$. Thermogravimetry (TG) and differential scanning calorimetry (DSC) of the samples were carried out at ambient atmospheric conditions at temperatures of up to $800^{\circ} \mathrm{C}$ (STA 409 PC Luxx, Netzsch). Hydrolytic stability of the MPP compounds was studied according to the semi-dynamic test [6]. Test conditions: monolithic sample, leaching agent - bidistilled water $(\mathrm{pH} 6.2 \pm 0.1)$, temperature is $23 \pm 2{ }^{\circ} \mathrm{C}$, periodic replacement of the leaching agent at 1, 3, 7, 10, 14, 21, 28 and 90 (for $\mathrm{Mg}, \mathrm{K}$, P) days from the beginning of the experiment. Water composition for leaching experiments, $\mathrm{mg} / \mathrm{l}: \mathrm{Na}-0.03$; $\mathrm{Al}-0.02 ; \mathrm{K}-0.005 ; \mathrm{Li}-0.002 ; \mathrm{Ca}-0.013 ; \mathrm{Fe}-0.001$; $\mathrm{Mg}-0.001 ; \mathrm{Ba}-0.003 ; \mathrm{P}-0.004 ; \mathrm{Si}-0.004$ et al. The content of ${ }^{239} \mathrm{Pu}$ and ${ }^{152} \mathrm{Eu}$ in aqueous solutions after leaching was determined by $\alpha$ - and $\gamma$-ray spectrometry (Canberra), respectively; the content of main structure-forming elements - by atomic emission spectrometry with inductively coupled plasma (ICP-AES) (iCAP-6500 Duo, Thermo Scientific). The leaching mechanism of the structure-forming elements of the MPP compound (magnesium, potassium, phosphorus) was evaluated according to the de Groot and van der Sloot model [7], that can be expressed by the following linear Eq. (2):

$$
\log \left(\mathrm{B}_{\mathrm{i}}\right)=\mathrm{A} \cdot \log (\mathrm{t})+\mathrm{const}
$$

where $B_{i}$ - the total yield of an element $i$ from the sample during contact with water, $\mathrm{mg} / \mathrm{m}^{2} ; \mathrm{t}$ - contact time, days.

Values of the coefficient A (line slope) in Eq. (2) correspond to the following elements leaching mechanisms: $<0.35$ - surface wash off (or a depletion if it found in the middle or at the end of the test); 0.35-0.65diffusion transport; $>0.65$ - surface dissolution [8].

\section{Results and discussion}

\subsection{Phase composition, structure and surface morphology of the MPP compounds}

The XRD analysis results revealed that the main crystalline phase of the studied samples, of both the blank MPP matrix and the MPP compounds containing macroquantities of metals and ammonium is a mineral-like analogue of the K-struvite $\left(\mathrm{MgKPO}_{4} \cdot 6 \mathrm{H}_{2} \mathrm{O}\right)$ or struvite $\left(\mathrm{MgNH}_{4} \mathrm{PO}_{4} \cdot 6 \mathrm{H}_{2} \mathrm{O}\right)$. The $\mathrm{KNO}_{3}$ phase (niter) is formed in the MPP compounds as a result of solidification of aqueous nitrates solutions and solutions simulating ILW. That indicates the substitution of potassium by other metal and ammonium cations and is confirmed by the presence of various crystalline phosphate phases in the samples, such as: $\mathrm{MgCsPO}_{4} \cdot 6 \mathrm{H}_{2} \mathrm{O}, \mathrm{Sr}_{3}\left(\mathrm{PO}_{4}\right)_{2}, \quad \mathrm{MgNaPO}_{4} \cdot 6 \mathrm{H}_{2} \mathrm{O}, \mathrm{Na}_{3} \mathrm{PO}_{4}$ (olympite), $\mathrm{LaPO}_{4} \cdot 0.5 \mathrm{H}_{2} \mathrm{O}$ (rhabdophane-(La)). SEM analysis demonstrates that MPP matrix is composed of crystalline particles predominantly with a size of 2-10 $\mu \mathrm{m}$ (Figure 1). The average elemental composition of the matrix corresponds to $\mathrm{MgKPO}_{4} \cdot 6 \mathrm{H}_{2} \mathrm{O}$, but the composition of single particles may vary. Some of the analyzed areas on the matrix surface are enriched in $\mathrm{Mg}$ and $\mathrm{P}$ and have an average composition of $\mathrm{Mg}_{1.16} \mathrm{~K}_{0.68} \mathrm{PO}_{4} \cdot 4.5 \mathrm{H}_{2} \mathrm{O}$, which can correspond to a mixture of $\mathrm{K}$-struvite and $\mathrm{Mg}_{3}\left(\mathrm{PO}_{4}\right)_{2} \cdot 2.6 \mathrm{H}_{2} \mathrm{O}$ in a molar ratio of 4.3/1. At the same time, $\mathrm{Mg}$-depleted particles with an estimated composition $\mathrm{Mg}_{0.62} \mathrm{KH}_{0.76} \mathrm{PO}_{4} \cdot 3.8 \mathrm{H}_{2} \mathrm{O}$ were found, which corresponds to a mixture of $\mathrm{K}$-struvite and unreacted $\mathrm{KH}_{2} \mathrm{PO}_{4}$ (Eq. 1), in a molar ratio of 1.6/1. However, an intrinsic phase of unreacted $\mathrm{KH}_{2} \mathrm{PO}_{4}$ has not been revealed by $\mathrm{X}$-ray diffraction. Nevertheless, the presence of this phase in a small amount (usually no more than 1-2 wt \%) cannot be ruled out.

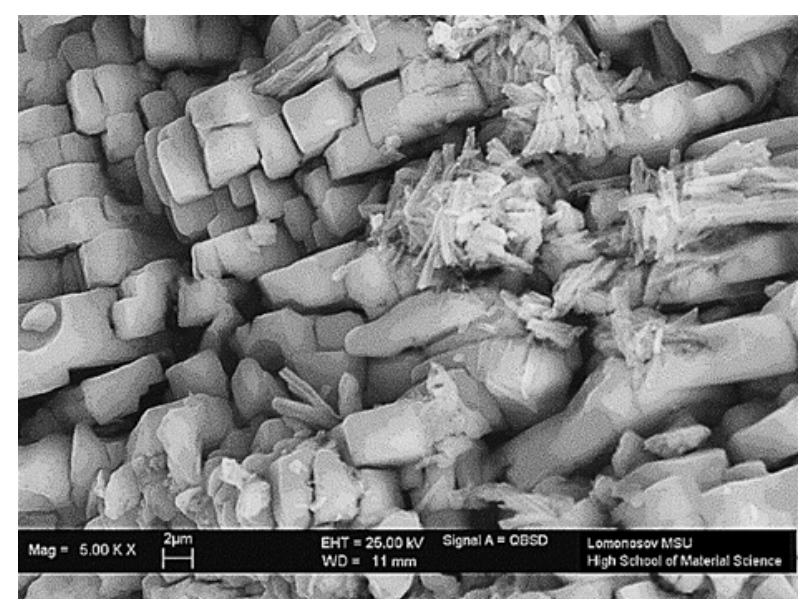

Figure 1. SEM image of the MPP matrix in back-scattering mode.

Cesium was localized in single inclusions in the compound, which also contain phosphorus and oxygen. Recently, Wagh et al. [9] suggested that $\mathrm{Mg}\left(\mathrm{Cs}_{\mathrm{x}} \mathrm{K}_{1-\mathrm{x}}\right) \mathrm{PO}_{4} \cdot 6 \mathrm{H}_{2} \mathrm{O}$ is formed in the MPP compound during solidification of a cesium-containing solution. We have observed that after solidification of a concentrated 
cesium nitrate solution in the MPP compound contains, along with cesium nitrate, also phosphate compounds with structure similar to K-struvite and newberyite minerals where potassium is replaced by cesium, for example, $\quad \mathrm{Mg}_{0.97} \mathrm{~K}_{0.29} \mathrm{Cs}_{0.75} \mathrm{PO}_{4} \cdot 6.3 \mathrm{H}_{2} \mathrm{O}$ and $\mathrm{Mg}_{0.55} \mathrm{~K}_{0.38} \mathrm{Cs}_{0.77} \mathrm{H}_{0.75} \mathrm{PO}_{4} \cdot 2.8 \mathrm{H}_{2} \mathrm{O}$, respectively. In addition, we have found areas containing up to 23.8 at.\% of cesium, that can indicate the presence of $\mathrm{Cs}_{3} \mathrm{PO}_{4}$ particles in the compound.

The strontium distribution in the MPP compound after solidification of a concentrated strontium nitrate solution corresponds to the distribution of phosphorus and magnesium that confirms the formation of their phosphate compounds. Strontium is bound in the structure of $\mathrm{K}$-struvite, containing up to 5.5 at.\% of strontium $\left(\mathrm{Mg}_{0.6} \mathrm{~K}_{0.23} \mathrm{Sr}_{0.69} \mathrm{PO}_{3.91} \cdot 6.1 \mathrm{H}_{2} \mathrm{O}\right)$, and also presents in the form of $\mathrm{Sr}_{3}\left(\mathrm{PO}_{4}\right)_{2}$. Lanthanum, like cesium and strontium, forms a number of mixed phosphate compounds in the MPP compound, including K-struvite analogs $\left(\mathrm{Mg}_{0.60} \mathrm{~K}_{0.68} \mathrm{La}_{0.36} \mathrm{PO}_{4} \cdot 6.3 \mathrm{H}_{2} \mathrm{O}\right)$ and anhydrous mixed orthophosphate $\left(\mathrm{Mg}_{0.55} \mathrm{~K}_{0.70} \mathrm{La}_{0.44} \mathrm{PO}_{4.06}\right)$.

Thus, the example of Cs, $\mathrm{Sr}$, and La has shown that the immobilization of RW components in the MPP compounds is possible due to their chemical binding in low soluble phosphates, which should provide high stability of the synthesized compounds towards leaching of these metals.

\subsection{Mechanical strength, thermal and radiation stability of the MPP compounds}

Compressive strength of the synthesized MPP compounds has an average value of $15 \pm 3 \mathrm{MPa}$. Their strength decreased to $10 \pm 2 \mathrm{MPa}$ after 30 thermal cycles of freezing/thawing in the range from -40 to $+40^{\circ} \mathrm{C}$, and also after a 90-days immersion in water and after irradiation with an electron beam (up to a dose of $1 \mathrm{MGy}$ ), which nevertheless corresponds the regulatory requirements for cement compounds - at least $5 \mathrm{MPa}$.

The addition of 20-40 wt.\% of mineral modifiers (wollastonite, bentonite and zeolite) into the MPP compound results in an increase of its mechanical strength (by 2-3 times), as well as its thermal stability. For example, a compound containing $38 \mathrm{wt} \%$ of wollastonite had a compressive strength of about 10.0 $\mathrm{MPa}$ even after heating at $450^{\circ} \mathrm{C}$ for 4 hours. At the same time, it was observed that heating of the MPP compound is accompanied by a mass loss (Figure 2, TG curve), evidently due to its dehydration - the maximum of endothermic effect corresponds to $120^{\circ} \mathrm{C}$ (Figure 2, DSC curve).

Application of the dehydrated MPP compounds for the disposal of radioactive waste will not lead to the formation of explosive radiolytic hydrogen. Earlier, we have demonstrated [4] an extremely low chemical yield of hydrogen $\left(0.004 \mathrm{H}_{2}\right.$ molecules/100 eV) from the MPP compound after curing the solution simulating highly saline HLW. A similar effect was described by Ershov et al. [10] during the $\gamma$-irradiation of cement compounds containing a simulator of nitrate-containing RW, which was explained by the capture of radical products of water radiolysis by nitrate ions.

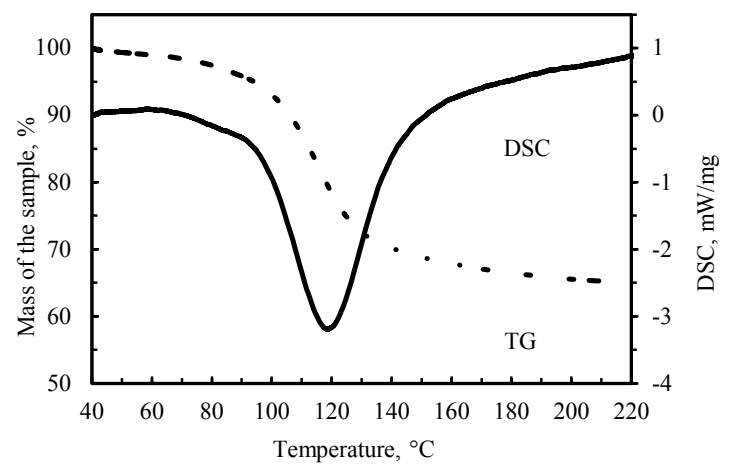

Figure 2. Thermal stability of the MPP compound according to TG/DSC data.

\subsection{Hydrolytic stability of the MPP compounds}

It was found that the $\mathrm{pH}$ values of the resulting solutions obtained after the MPP compounds contact with bidistilled water were in the range 8.3-8.5. At the same time, the $\mathrm{pH}$ values of the solutions obtained after the leaching of the MPP compounds containing ILW simulators or containing $38 \mathrm{wt} \%$ of wollastonite increased to $9.5-10.5$, which can be explained by the hydrolysis of the formed easily soluble phosphate phases (e.g., $\mathrm{Na}_{3} \mathrm{PO}_{4}$ ) and wollastonite.

It was observed that the leaching of the main elements of the MPP compounds ( $\mathrm{Mg}, \mathrm{P}$ and $\mathrm{K})$ is controlled by different mechanisms (Figure 3 and Table 1) during first 90 days of contact with water. In the first 10 days, the leaching of $\mathrm{Mg}, \mathrm{K}$, and $\mathrm{P}$ occurs due to surface wash off from the sample surface, with the coefficients A (Eq. 2) equal to $-0.04,0.22$, and 0.13 , respectively. Higher amount of potassium and phosphorus released from the MPP compound in comparison with magnesium is probably due to the dissolution of unreacted $\mathrm{KH}_{2} \mathrm{PO}_{4}$ (Eq. $1)$. In the subsequent 80 days, the surface layer of the sample underwent gradual depletion of $\mathrm{K}$ and $\mathrm{P}$ (coefficients $A-0.69$ and -0.53 , respectively), and the $\mathrm{Mg}$ leaching occurred via diffusion from the internal layers $(A=0.39)$.

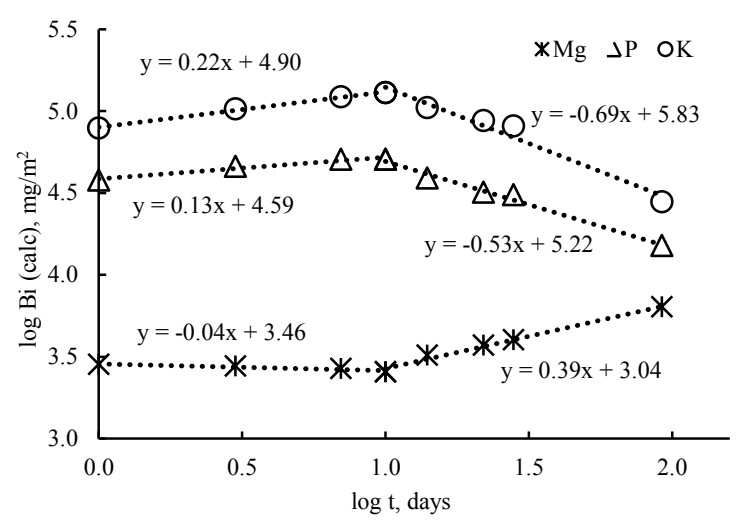

Figure 3. Dependence of the release of the main elements of the MPP compound on the contact time with water. 
Table 1. The mechanism of components leaching of the MPP compound according to Eq. (2).

\begin{tabular}{cccc}
\hline $\begin{array}{c}\text { Components } \\
\text { of the MPP } \\
\text { compound }\end{array}$ & $\begin{array}{c}\text { Contact time } \\
\text { with water, } \\
\text { days }\end{array}$ & $\begin{array}{c}\text { Line slope } \\
\text { (Fig. 3) }\end{array}$ & $\begin{array}{c}\text { Leaching } \\
\text { mechanism }\end{array}$ \\
\hline $\mathrm{Mg}$ & $0-10$ & -0.04 & wash off \\
& $10-90$ & 0.39 & diffusion \\
$\mathrm{K}$ & $0-10$ & 0.22 & wash off \\
& $10-90$ & -0.69 & depletion \\
$\mathrm{P}$ & $0-10$ & 0.13 & wash off \\
& $10-90$ & -0.53 & depletion \\
\hline
\end{tabular}

Comparison of the data on hydrolytic stability of various MPP compounds (Table 2) demonstrates that the effect of the chemical composition of the solidified solution on the leaching of the main elements of the MPP compound is negligible. The differential leaching rate of $\mathrm{Mg}, \mathrm{K}$ and $\mathrm{P}$ does not exceed $1.3 \cdot 10^{-4}, 1.4 \cdot 10^{-3}$ and $8.7 \cdot 10^{-4} \mathrm{~g} /\left(\mathrm{cm}^{2} \cdot\right.$ day $)$, respectively. The increase in the integral leaching rate of potassium from the samples with ILW simulator (MPP-ILW) and with La (MPP-La) as well as of magnesium from the MPP-ILW sample in comparison with blank MPP matrix (Table 2) can be attributed with the possible formation of individual compounds of these elements, first of all $\mathrm{KNO}_{3}$, and also possibly $\mathrm{Mg}\left(\mathrm{H}_{2} \mathrm{PO}_{4}\right)_{2} \cdot \mathrm{xH}_{2} \mathrm{O}, \quad \mathrm{Mg}_{3}\left(\mathrm{PO}_{4}\right)_{2} \cdot \mathrm{xH}_{2} \mathrm{O}$, $\mathrm{Mg}_{2} \mathrm{PO}_{4}(\mathrm{OH})$ in first days of the MPP contact with water and further dissolution of these individual compounds.

Table 2. Differential and integral leaching rates of the main elements of the MPP compounds (28 days of contact with water).

\begin{tabular}{cccc}
\hline \multirow{2}{*}{ Element } & \multicolumn{2}{c}{$\begin{array}{c}\text { Differential/integral leaching rate of elements } \\
\text { from the MPP compounds, } \mathrm{g} /\left(\mathrm{cm}^{2} \cdot \text { day }\right)\end{array}$} \\
\cline { 2 - 4 } & MPP & MPP-La & MPP-ILW \\
\hline \multirow{2}{*}{$\mathrm{Mg}$} & $7.7 \cdot 10^{-5} /$ & $3.4 \cdot 10^{-5} /$ & $1.3 \cdot 10^{-4} /$ \\
& $2.3 \cdot 10^{-4}$ & $2.3 \cdot 10^{-4}$ & $8.2 \cdot 10^{-4}$ \\
$\mathrm{~K}$ & $1.2 \cdot 10^{-3} /$ & $1.4 \cdot 10^{-3} /$ & $9.6 \cdot 10^{-4} /$ \\
& $5.8 \cdot 10^{-3}$ & $9.3 \cdot 10^{-3}$ & $1.2 \cdot 10^{-2}$ \\
$\mathrm{P}$ & $5.5 \cdot 10^{-4} /$ & $8.7 \cdot 10^{-4} /$ & $5.1 \cdot 10^{-4} /$ \\
& $3.2 \cdot 10^{-3}$ & $2.0 \cdot 10^{-3}$ & $3.9 \cdot 10^{-3}$ \\
$\mathrm{La}$ & - & $6.4 \cdot 10^{-6} /$ & - \\
\hline
\end{tabular}

The high hydrolytic stability of the MPP compounds towards leaching of radionuclides has been demonstrated (Figure 4) as the main criterion of its suitability for RW storage/disposal. The differential and integral leaching rates from the MPP-ILW samples after 28 days of their contact with water were: for ${ }^{239} \mathrm{Pu}-2.1 \cdot 10^{-6}$ and $8.1 \cdot 10^{-6}$ $\mathrm{g} /\left(\mathrm{cm}^{2} \cdot\right.$ day $)$, respectively; for ${ }^{152} \mathrm{Eu}-1.4 \cdot 10^{-4}$ and $1.1 \cdot 10^{-3} \mathrm{~g} /\left(\mathrm{cm}^{2} \cdot\right.$ day $)$, respectively. At the same time, the addition of wollastonite into the MPP compound (sample MPP-ILW_wol, Figure 4) leads to a decrease in the differential and integral leaching rates of ${ }^{152} \mathrm{Eu}$ to $6.5 \cdot 10^{-5}$ and $2.6 \cdot 10^{-4} \mathrm{~g} /\left(\mathrm{cm}^{2} \cdot\right.$ day $)$, respectively.

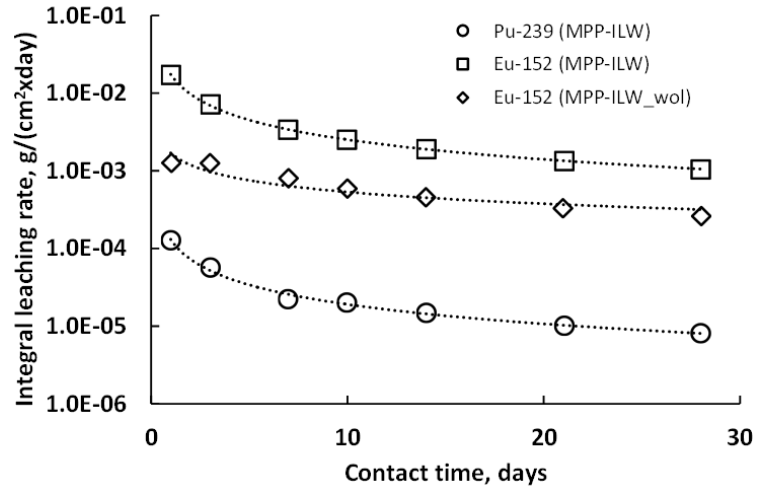

Figure 4. Integral leaching rate of ${ }^{239} \mathrm{Pu}$ and ${ }^{152} \mathrm{Eu}$ from the MPP-ILW samples, including samples containing $38 \mathrm{wt} . \%$ of wollastonite (MPP-ILW_wol).

\section{Conclusion}

As a result of the research, high mechanical, thermal, radiation resistance (compressive strength no less than 10 $\mathrm{MPa}$ ) and hydrolytic stability (differential leaching rates of ${ }^{239} \mathrm{Pu}-2.1 \cdot 10^{-6} \mathrm{~g} /\left(\mathrm{cm}^{2} \cdot\right.$ day $\left.)\right)$ of the MPP compounds were established. It should be specially noted that the possible practical application the MPP matrix for ILW and HLW management, unlike glass or ceramics, does not require the installation of expensive high-temperature electric furnaces, whose liquidation after end of use is a complex radioecological task, which is not currently being solved. This allows us to consider the MPP matrix as a new promising material for industrial solidification of actinide-containing LRW.

\section{Acknowledgements}

The study was financially supported by the Russian Science Foundation (project № 16-13-10539).

\section{References}

[1] S.V. Stefanovsky, S.V. Yudintsev, S.E. Vinokurov and B.F. Myasoedov, Chemical-technological and mineralogical-geochemical aspects of the radioactive waste management, Geochemistry International 54 (13) (2016), pp. 1136-1156.

[2] S.V. Yudintsev, S.V. Stefanovsky and R.C. Ewing, Actinide host phases as radioactive waste forms. In: Structural Chemistry of Inorganic Actinide Compounds, Eds. Krivovichev S.V., Burns P.C., Tananaev I.G., Elsevier B.V., Amsterdam, (2007), pp. 457-490.

[3] A.S. Wagh, Chemically Bonded Phosphate Ceramics. Twenty-First Century Materials with Diverse Applications, Elsevier, Oxford (2004). 300 p., ISBN 0080445055.

[4] S.E. Vinokurov, Yu.M. Kulyako, O.M. Slyuntchev, S.I. Rovny and B.F. Myasoedov, Low-temperature immobilization of actinides and other components of high-level waste in magnesium potassium phosphate matrices, J. Nuclear Materials 385 
(2009), pp. 189-192.

[5] S. Graeser, W. Postl, H.-P. Bojar, P. Berlepsch, T. Armbruster, T. Raber, K. Ettinger and F. Walter, Struvite-(K), $\mathrm{KMgPO}_{4} \cdot 6 \mathrm{H}_{2} \mathrm{O}$, the potassium equivalent of struvite - new mineral, Eur. J. Mineralogy 20 (2008) pp. 629-63.

[6] GOST R 52126-2003. Radioactive Waste. Determination of Chemical Stability of Cure High Level Waste by Method of Long-term Leaching. Gosstandart of Russia, Moscow (2003). [in Russian]

[7] G.J. de Groot and H.A. van der Sloot, Determination of leaching characteristics of waste materials leading to environmental product certification. In T.M. Gilliam, G. Wiles (Eds.), Stabilization and Solidification of Hazardous, Radioactive and Mixed Wastes, ASTMSTP 1123, ASTM, Philadelphia vol. 2, (1992), pp. 149-170.
[8] J. Torras, I. Buj, M. Rovira and J. de Pablo, Semi-dynamic leaching tests of nickel containing wastes stabilized/solidified with magnesium potassium phosphate cements, J. of Hazardous Materials 186 (2011), pp. 1954-1960.

[9] A.S. Wagh, S.Y. Sayenko, V.A. Shkuropatenko, R.V. Tarasov, M.P. Dykiy, Y.O. Svitlychniy, V.D. Virych and E.A. Ulybkina, Experimental study on cesium immobilization in struvite structures, $J$. of Hazardous Materials 302 (2016), pp. 241-249.

[10] B.G. Ershov, T.K. Yurik, G.L. Bykov, A.V. Gordeev, P.V. Kozlov, O.M. Slunchev, S.I. Rovny and Y.V. Glagolenko, Immobilization of medium level and high level wastes in cement matrices: impact of irradiation and gas formation and radionuclide leaching, Radiation Safety Problems 1 (2008), pp. 3-15. [in Russian]. 